\title{
KOMUNIKASI POSITIF SEBAGAI UPAYA PERLINDUNGAN ANAK DARI KEKERASAN MELALUI KEGIATAN PARENTING DI MASYARAKAT KEL. CEMPAKA PUTIH KEC. CIPUTAT TIMUR TANGSEL PROVINSI BANTEN
}

\author{
Susianty Selaras Ndari ${ }^{1}$ Chandrawaty $^{2}$, Kibitiah ${ }^{3}$, Erik Wahyudin ${ }^{4}$ \\ ${ }^{1}$ Universitas Muhammadiyah Prof. DR. HAMKA \\ susilaras@uhamka.ac.id \\ ${ }^{2}$ Universitas Muhammadiyah Prof. DR. HAMKA \\ chandrawatydikdas@yahoo.com \\ ${ }^{3}$ Universitas Muhammadiyah Prof. DR. HAMKA \\ Kibitia2703@gmail.com \\ ${ }^{4}$ STKIP Muhammadiyah Kuningan \\ Erikwahyudin12@gmail.com
}

\begin{abstract}
ABSTRAK
Tujuan program kemitraan masyarakat Komunikasi Positif Sebagai Upaya Perlindungan Anak Dari Kekerasan Melalui Kegiatan Parenting Di Masyarakat Kec. Cempaka Putih Kec. Ciputat Timur Tangsel adalah untuk untuk mengetahui gambaran hasil kegiatan pentingnya komunikasiorangtua dan anak.terbentuk kader/the agent of change yang terampil untuk menindaklanjuti apabila terjadi kekerasan dalam pengasuhan, agar terjadinya perubahan paradigma orangtua dalam pengasuhan anak tanpa kekerasan. Kegiatan program kemitraan masyarakat Komunikasi Positif Sebagai Upaya Perlindungan Anak Dari Kekerasan Melalui Kegiatan Parenting Di Kec. Cempaka Putih Kec. Ciputat Timur Tangsel dilakukan melalui proses pelatihan dengan metode partisipatif. Peserta pelatihan terdiri dari 150 orang yang terdiri dari tokoh masyarakat dan warga sekitar. Tahapan kegiatan pelatihan yang disusun oleh tim (PKM) sebagai berikut: pertama, bersama mitra mendata potensi peserta dan melakukan pemetaan potensi peserta untuk keberlanjutan program. Kedua, menyiapkan modul pelatihan komunikasi positif dan perlindungan anak dari kekerasan melalui pengasuhan dan deteksi dini kekerasan terhadap anak, dan Standart Operational Prosedure menjadi first aid untuk kasus kekerasan terhadap anak di wilayahnya. Ketiga, konsultasi dengan mitra KPAI untuk isi materi. Keempat, pelaksanaan kegiatan pelatihan dan rencana tindak lanjut kegiatan. Kelima, evaluasi kegiatan dan membuat luaran dari pengabdian baik berupa artikel maupun modul.
\end{abstract}

Keywords: komunikasi, pengasuhan positif, kekerasan anak, parenting

PENDAHULUAN

\section{A. Latar Belakang}

Anak merupakan penerus generasi bangsa yang harus disiapkan kualitasnya baik dari aspek intelektual, social emosi dan karakternya sejak sedini mungkin agar menjadi generasi yan berkualitas. Mempersiapkan generasi yang berkualitas tentunya dilakukan melalui pengasuhan yang 
Susianty Selaras Ndari, dkk, KOMUNIKASI POSITIF SEBAGAI UPAYA PERLINDUNGAN ANAK DARI KEKERASAN MELALUI KEGIATAN PARENTING DI MASYARAKAT KEL. CEMPAKA PUTIH KEC. CIPUTAT TIMUR TANGSEL PROVINSI BANTEN . Early Childhood Vol. 3 No. 1, Mei 2019

yang berkualitas pula artinya bahwa orangtua dalam melaksanakan kewajiban pengasuhan harus dibekali dengan ilmu pengetahuan tentang pengasuahan agar dalam pelaksanaan tidak terjadi malpraktek pengasuhan yang berakibat terjadinya kekerasan pada anak yang diasuh.

Masyarakat Kelurahan cempaka putih kecamatan ciputat timur yang berada di gang swadaya merupakan masyarakat marginal (masyrakat dengan ekonomi rendah dan banyak beredar narkoba). Sebagaian besar warga masyarakat bekerja secara serabutan ada yang menjadi pedagang asongan, pemulung, tukang becak, buruh cuci serta beberapa menjdi guru TK/PAUD di lembaga setempat.

Tabel. 1.2

Berikut data awal pekerjaan Masyarakat gg. swadaya Cempaka putih ciputat timur Tangerang selatan :

\begin{tabular}{|c|c|}
\hline Pekerjaan orangtua & $\begin{array}{c}\text { Jumlah } \\
\text { anak }\end{array}$ \\
\hline Guru TK/PAUD & 6 \\
\hline Pedagang Asongan & 35 \\
\hline Pemulung & 15 \\
\hline $\begin{array}{c}\text { Serabutan (sopir } \\
\text { lepas,buruh cuci dll) }\end{array}$ & 50 \\
\hline $\begin{array}{c}\text { Total jumlah anak usia } \\
\text { dini }\end{array}$ & 156 \\
\hline
\end{tabular}

Sumber: Hasil wawancara dengan tokoh masyarakat Dr. H. Uzt. Memed Sururi dilakukan pada 18 Januari 2018
Menurut hasil wawancara yang dilakukan kepada salah satu tokoh masyarakat setempat, bahwa keseharian orangtua dan anak- anak berinteraksi dengan berbagai macam orang dengan perilaku yang tidak sesuai norma agama dan norma masyarakat. Hal ini berdampak pada cara orangtua mengasuh anak misalnya mengatakan anaknya "bodoh kamu, dasar kamu,", dan ancaman- ancaman berupa lisan seperti: "awas ya, nanti ibu pukul kamu", mengumpat, bahkan tidak jarang orangtua melakukan pemukuluan fisik kepada anaknya.

Salah satu proses menyiapkan anak sebagai generasi penerus diantaranya dengan memberikan pengasuhan terbaik. Berdasarkan Undang - Undang Perlindungan Anak Pasal 7 ayat 1 menyebutkan bahwa " Setiap anak berhak untuk mengetahui orang tuanya, dibesarkan, dan diasuh oleh orang tuanya sendiri". Artinya, pengasuhan menjadi dominan orang tua. Tugas dan fungsi mengasuh anak tidak akan gugur oleh waktu maupun perubahan relasi perkawinan orang tua. Hubungan orang tua dan anak tidak akan pernah berakhir sampai kapanpun.

Dalam pengasuhan orangtua lebih banyak melakukan dengan cara tradisioanal seperti warisan yang diturunkan secara turun temurun dari cara orangtan mengasuh dahulu. Tidak jarang kemudia orangtua menyesali pengasuhan yang dilakukannya karena 
Susianty Selaras Ndari, dkk, KOMUNIKASI POSITIF SEBAGAI UPAYA PERLINDUNGAN ANAK DARI KEKERASAN MELALUI KEGIATAN PARENTING DI MASYARAKAT KEL. CEMPAKA PUTIH KEC. CIPUTAT TIMUR TANGSEL PROVINSI BANTEN . Early Childhood Vol. 3 No. 1, Mei 2019

sebgaian besar orangtua belum mengetahuai pengasuhan yang baik dan benar sesuai keilmuan.

Berdasarkan penelitian tentang Kualitas Pengasuhan yang dilakukan oleh Komisi Perlindungan Anak Indonesia KPAI (2015) menyebutkan bahwa hanya kurang lebih 27,9\% Ayah dan $36,9 \%$ ibu yang mencari informasi tentang pengasuhan sebelum memiliki anak. Ternyata setelah menikah, ada peningkatan $11 \%$ dari ayah dan 19,3\% dalam hal mencari informasi terkait pengasuhan. Namun demikian, masih ada $60,1 \%$ ayah dan $43,8 \%$ ibu yang tidak mencari informasi terkait pengasuhan. Selain itu, sebanyak $66,4 \%$ Ayah dengan pola pengasuhan yang dulu dilakukan oleh kedua orang tuanya. Tidak semua pola pengasuhan orang tua tidak baik, namun perlu banyak pembaharuan dari para orang tua hari ini untuk mengasuh anak. Berikut seperti terlihat dalam table:

Tabel.1.2

Informasi Pengasuhan Orangtua Indonesia

\begin{tabular}{|c|c|c|}
\hline Aspek & Ayah & Ibu \\
\hline $\begin{array}{c}\text { Mencari informasi } \\
\text { tentang pengasuhan } \\
\text { sebelum memiliki } \\
\text { anak. }\end{array}$ & $27,9 \%$ & $36,9 \%$ \\
\hline $\begin{array}{c}\text { Setelah menikah } \\
\text { Ayah dan ibu yang } \\
\text { tidak mencari } \\
\text { informasi terkait } \\
\text { pengasuhan }\end{array}$ & $60,1 \%$ & $43,8 \%$ \\
\hline
\end{tabular}

\begin{tabular}{|c|c|c|}
\hline Pola pengasuhan & $66,4 \%$ & \\
yang dulu & & \\
dilakukan oleh & & \\
kedua orang & & \\
tuanya. & & \\
\hline
\end{tabular}

( Sumber: KPAI)

Pengasuhan yang baik salah satunya dilakukan melalui komunikasi positif antar orangtua dan anak. Komunikasi yang baik sangat penting dalam hubungan antara orangtua dan anak. Karena melalui komunikasi orangtua dapat membangun hubungan yang menyenangkan dan positif. Dalam penelitian terkini juga menyebutkan bahwa anak yang tumbuh dengan komunikasi positif dengan orangtua cenderung memiliki kepribadian, daya tahan terhadap stress dan self esteem yang lebih baik dibandingkan dengan anak yang memiliki hubungan dan komunikasi yang buruk dengan orangtua.

Kemampuan komunikasi dibutuhkan dalam hubungan orangtua dan anak, dimulai dari sejak dini hingga dewasa. Komunikasi yang baik adalah kunci dari hubungan yang saling menghargai dan terciptanya pribadi anak yang sehat serta terciptanya tumbuh kembang yang optimal. Kemampuan komunikasi dibutuhkan dalam hubungan orangtua dan anak, dimulai dari sejak dini hingga dewasa. Komunikasi yang baik adalah kunci dari hubungan yang saling menghargai dan terciptanya pribadi anak yang sehat 
Susianty Selaras Ndari, dkk, KOMUNIKASI POSITIF SEBAGAI UPAYA PERLINDUNGAN ANAK DARI KEKERASAN MELALUI KEGIATAN PARENTING DI MASYARAKAT KEL. CEMPAKA PUTIH KEC. CIPUTAT TIMUR TANGSEL PROVINSI BANTEN . Early Childhood Vol. 3 No. 1, Mei 2019

serta terciptanya tumbuh kembang yang optimal.

Data KPAI (2015) menyebutkan bahwa indeks Ketahanan Keluarga Bidang Pengasuhan di Indonesia masih belum cukup baik. Indeks yang masih memiliki nilai dibawah 4 diantaranya terkait dengan pengetahuan tentang pengasuhan, pola komunikasi, akses anak terhadap media digital, dan pencegahan terhadap kekerasan. Pada situasi diatas orang tua masih belum melakukan dengan baik atau belum memiliki pengetahuan yang baik. Sedangkan yang cukup baik yaitu untuk pemenuhan hak dasar, dan partisipasi anak.

Tabel 1.3

Indeks Ketahanan Keluarga Bidang

Pengasuhan

\begin{tabular}{|l|c|}
\hline $\begin{array}{l}\text { Indeks Ketahanan Bidang } \\
\text { Pengasuhan }\end{array}$ & Nilai Indeks \\
\hline $\begin{array}{l}\text { Persiapan pengasuhan } \\
\text { pra nikah dan fase awal }\end{array}$ & 3,53 \\
\hline Pemenuhan hak dasar & 4,05 \\
\hline Penanaman nilai dasar & 4,03 \\
\hline Pola Komunikasi & 3,84 \\
\hline $\begin{array}{l}\text { Akses anak terhadap } \\
\text { media digital }\end{array}$ & 3,45 \\
\hline $\begin{array}{l}\text { Pencegahan terhadap } \\
\text { kekerasan }\end{array}$ & 3,82 \\
\hline Partisipasi anak & 4,00 \\
\hline
\end{tabular}

Indeks memiliki nilai 1 - 5 dengan angka terendah 1 dan tertinggi 5

(sumber: KPAI)

Orang tua dengan pemahaman pola asuh yang baik dan benar sangat penting dalam pengasuhan anak. Salah satu keterampilan yang diperlukan dalam pengasuhan adalah keterampilan komunikasi dengan anak. Negara dan masyarakat harus dapat memampukan orang tua agar cakap mengasuh. Melihat kondisi dan permasalahan di masyarakat di kel. Cempaka putuh ciputat timur tangsel yang cukup memprihatinkan dalam berkomunikasi dengan anak, maka tim PKM Universitas Muhammadiyah Prof. DR. HAMKA, merasa terpanggil untuk memberikan kontribusi dalam pemberdayaan orang tua agar memiliki keterampilan komunikasi yang baik dan benar dalam pengasuhan.

\section{KAJIAN TEORITIK}

\section{A. Definisi komunikasi}

Komunikasi merupakan sebuah mesin dalam peran social, oleh karenanya komunikasi dapat menyebabkan hubungan social relative baik atau buruk tergantung bagaimana komunukasi dapat membangun hubungan positif daintara orang- orang di sekitar. Komunikasi melibatkan mendengarkan, ketersediaan, pemahaman, saling menghormati dan emosi. Intinya, berkomunikasi berarti mengetahui bagaimana memberi dan mengetahui bagaimana menerima. Dapat didefinisikan secara praktis, komunikasi adalah proses alami penyampaian gagasan, informasi, emosi dan perasaan dari satu orang ke orang 
Susianty Selaras Ndari, dkk, KOMUNIKASI POSITIF SEBAGAI UPAYA PERLINDUNGAN ANAK DARI KEKERASAN MELALUI KEGIATAN PARENTING DI MASYARAKAT KEL. CEMPAKA PUTIH KEC. CIPUTAT TIMUR TANGSEL PROVINSI BANTEN . Early Childhood Vol. 3 No. 1, Mei 2019

lain dalam jumlah waktu tertentu (Luciana, Constantineanu, Ielics, \& Popa, 2012). Selanjutnya bahwa komunikasi sebagai proses penyampaian suatu pernyataan oleh seseorang kepada orang lain. Menurut Halah dalam Fann al-tawwashul fi alIslam menyebut bahwa komunikasi adalah hubungan terbaik. Definisi ini lebih menekankan kepada kualitas komunikasi dalam tiga bentuk yaitu komunikasi dengan Pencipta, komunikasi dengan diri sendiri, dan komunikasi dengan sesama manusia (Harjani, 2014).Berkomunikasi antara orang tua dan anak-anak tidak selalu sulit tetapi membutuhkan keterampilan, ketersediaan waktu orangtua, sehingga tidak terburu- buru pada akhirnya pesan yang akan disampaikan orangtua kepada anak atau sebaliknya akan dipahami.

Komunikasi memiliki peran penting dalam membangun hubungan orangtua dan anak baik anak normal ataupun anak dengan gangguan $A D H D$ attention-deficit / hyperactivity disorder (Wymbs \& Jr, 2010), penelitian yang dilakukan dengan sampel anak usia 1012 tahun dengan gangguan ADHD ratarata mereka hampir memiliki komunikasi negative. Dewasa ini klubklub olahraga ada dimana- mana baik dilakukan anak- anak muda maupun anak- anak TK hingga SMA. Hal tersebut membuktikan konteks ekstrakurikuler olahraga dapat dijadikan sarana komunikasi antara anak dan orangtua dan merupakan sarana interaksi keluarga, dapat dimaknai hal ini mencerminkan semakin banyaknya keluarga yang menjadikan olahraga sebagai bagian integral kehidupan kolektif mereka Grimm et al., 2017. Dalam hal ini penting untuk memahami faktor-faktor tersebut berdampak pada hubungan orangtua-anak di Indonesia melalui kegiatan ekstrakulikuler olahraga, dan bagaimana hal ini dapat terus terjadi di kehidupan sehari-hari di luar kegiatan olahraga. Komunikasi adalah aspek yang menonjol dari hubungan orangtua-anak yang mempengaruhi baik hubungan orangtua-anak dan pengalaman olahraga anak.

Dalam pengasuhan orangtua dituntut untuk melakukan kewajibannya dengan penuh kasih sayang, mengucapkan kata- kata lembut, tidak membentak, melotot atau mengomel. Orangtua sebagai orang dewasa yang ditemui anak di rumah menggunakan strategi komunikasi positif kepada anak. Seperti diketahui komunikasi positif orangtua dalam pengasuhan akan meningkatkan perilaku positif anak baik saat berinteraksi di dalam keluarga maupun dengan orang- orang yang berada di lingkungan sekitarnya. Pernyataan ini selaras dengan hasil penelitian yang dilakukan bahwa semakin banyak orang tua berkomunikasi dengan anak-anak, 
Susianty Selaras Ndari, dkk, KOMUNIKASI POSITIF SEBAGAI UPAYA PERLINDUNGAN ANAK DARI KEKERASAN MELALUI KEGIATAN PARENTING DI MASYARAKAT KEL. CEMPAKA PUTIH KEC. CIPUTAT TIMUR TANGSEL PROVINSI BANTEN . Early Childhood Vol. 3 No. 1, Mei 2019

semakin kuat anak-anak akan meningkatkan kemampuan komunikasi dan kemauan mereka berhubungan lebih baik dengan orang-orang di sekitar mereka (Runcan).

Melaksanakan pengasuhan orangtua dalam mendidik anak hendaknya dilakukan melalui komunikasi positif, dengan komunikasi positif berdampak akan meningkatnya kenyamanan anak kepada orangtuanya (Broberg, 2012 ). (Po Sen Chu, Donald A. Saucier, and Eric Hafne, 2010). Namun kenyatannya tidak dapt dipungkiri bahwa dalam pengasuhan pada beberapa orangtua melakukan kekerasan yang tanpa disadari terhadap anak- anaknya, Kekerasan terhadap anak bukan saja dilakukan orang tua, tapi bisa juga dilakukan orang-orang yang ada di lingkungannya.

\section{B. TUJUAN KOMUNIKASI}

Beberapa ahli berpendapat yang dikutip dari Liliweri, (1991:8) bahwa komunikasi memiliki tujuan sebagai berikut: 1) Social Change (perubahan sosial), 2) Attude Change (perubahan sikap), 3) Opinion Change (perubahan pendapat), dan 4) Behavior Change (perubahan tingkah laku). Komunikasi memiliki tujuan yaitu adalah tercapainya kesepahaman makna diantara kedua orang, atau lebih yang melakukan komunikasi selain itu juga dari proses komunikasi diharapkan terjadinya umpan balik (feedback) serta pesan-pesan yang hendak disampaikan sesuai yang diharapkan.

Terjadinya beberapa kekerasan dalam berkomunikasi barangkali dianggap hal yang biasan karena sudah menjadi budaya dalam masyarakat tertentu misalnya, memanggil anak dengan nada suara keras sperti pada masyarakat Batak, Panggilan Gua, Elu pada masyarakat Betawi, Intonasi yang tajam dan menekan dalam berkomunukasi pada masyarakat madura. Hal ini sejalan dengan penelitian studi kasus yang telah dilakukan bahwa setiap daerah berbeda satu sama lain karena tentunya memiliki budaya yang berbeda (Rini, Fardiah: 2016).

Selanjutnya bentuk- bentuk kekerasan yang terjadi dalam pengasuhan diantaranya: 1). Penelantaran. Penelantaran anak adalah di mana orang dewasa yang bertanggung jawab gagal untuk menyediakan kebutuhan memadai untuk berbagai keperluan, termasuk fisik (kegagalan untuk menyediakan makanan yang cukup, pakaian, atau kebersihan), 3) Kekerasan fisik. Guncangan terhadap seorang anak dapat menyebabkan sindrom guncangan bayi yang dapat mengakibatkan tekanan intrakranial, pembengkakan otak, cedera difus aksonal, dan kekurangan oksigen yang mengarah ke pola seperti gagal tumbuh, muntah, lesu, kejang, pembengkakan atau penegangan ubun- 
Susianty Selaras Ndari, dkk, KOMUNIKASI POSITIF SEBAGAI UPAYA PERLINDUNGAN ANAK DARI KEKERASAN MELALUI KEGIATAN PARENTING DI MASYARAKAT KEL. CEMPAKA PUTIH KEC. CIPUTAT TIMUR TANGSEL PROVINSI BANTEN . Early Childhood Vol. 3 No. 1, Mei 2019

ubun, rungan untuk mengulangi tindakan kekerasan setelah dewasa, bulimia nervosa,cedera fisik pada anak di antara masalah-masalah lainnya. 4). Kekerasan seksual sekitar $15 \%$ sampai $25 \%$ wanita dan $5 \%$ sampai $15 \%$ pria yang mengalami pelecehan seksual ketika mereka masih anak-anak. Kebanyakan pelaku pelecehan seksual adalah orang yang kenal dengan korban mereka; sekitar $30 \%$ adalah keluarga dari anak, paling sering adalah saudara, ayah, ibu, paman atau sepupu, sekitar $60 \%$ adalah kenalan teman lain seperti keluarga, pengasuh anak, atau tetangga; orang asing adalah yang melakukan pelanggar hanya sekitar $10 \%$ dari kasus pelecehan seksual anak. 5) Kekerasan Verbal/emosional. Korban kekerasan emosional dapat bereaksi dengan menjauhkan diri dari pelaku, internalisasi kata-kata kasar atau dengan menghina kembali pelaku penghinaan. Kekerasan emosional dapat mengakibatkan gangguan kasih sayang yang abnormal atau terganggu, kecenderungan korban menyalahkan diri sendiri (menyalahkan diri sendiri) untuk pelecehan tersebut, belajar untuk tak berdaya, dan terlalu bersikap pasif.

\section{Defini Parenting}

Komunikasi positif dengan anak dilakukan di rumah dan di sekolah. Lembaga Pendidikan dalam hal ini sekolah tidak dapat melaksanakan pengajaran kepada anak didik tanpa kerjasama dengan orangtua. Dalam upaya mensinergikan pendidikan di rumah dan di sekolah diperlukan manajemen parenting dengan melibatkan orangtua dalam mendidik anak, sehingga terjadi korelasi yang kuat apa yang diajarkan guru dengan orangtua. Meningkatkan pengetahuan orangtua melalui kegiatan parenting yang diselenggarakan sekolah salah satunya adalah mengajarkan ketrampilan berkomunikasi (Ndari, 2018). Dapat dimaknai komunikasi merupakan hal penting dalam pengasuhan anak.

\section{METODE PENELITIAN}

Pada penelitian ini digunakan teknik pre test dan post test dengan menggunakan instrument kuisioner kepada peserta pelatihan dan wawancara terstruktur kepada pimpinan dan tokoh masyarakat untuk mengukur peningkatan kapasitas, khususnya pada kapasitas kognitif atau pengetahuan, dari sebelum mengikuti pelatihan dan setelah mengikuti pelatihan pada orangtua yang telah mengikuti kegiatan pelatihan dalam upaya meningkatkan kominikasi positif dengan anak dalam pengasuhan. AnalisisData dilakukan dengan deskriptif analitik Penelitian yang melibatkan peneliti dalam proses penelitian dari awal sampai akhir dengan hasil penelitian berupa laporan. Dengan pelatihan ini, peserta diasumsikan akan mengalami 
Susianty Selaras Ndari, dkk, KOMUNIKASI POSITIF SEBAGAI UPAYA PERLINDUNGAN ANAK DARI KEKERASAN MELALUI KEGIATAN PARENTING DI MASYARAKAT KEL. CEMPAKA PUTIH KEC. CIPUTAT TIMUR TANGSEL PROVINSI BANTEN . Early Childhood Vol. 3 No. 1, Mei 2019

penambahan pengetahuan khususnya di bidang komunikasi positif dan deteksi dini kekerasan terhadap anak. Peserta pelatihan akan berjumlah 150 orang. Sample berusia 20-55 tahun mewakili jenis kelamin perempuan $80 \%$ dan lakilaki $20 \%$. Selain itu, hasil dari kegiatan ini juga dapat dilihat dari rencana tindak lanjut yang dirumuskan peserta. RTL ini bersifat kelompok dalam hal ini kader yang terbentuk akan melanjutkan kegiatan yang sama kepada masyarakat sekitar yang lebih luas.

\section{HASIL DAN PEMBAHASAN}

\section{A. Hasil Program Kemitraan Masyarakat}

1. Gambaran pelaksanaan kegiatan

(PKM) Komunikasi Positif Sebagai Upaya Perlindungan Anak Dari Kekerasan Melalui Kegiatan Parenting Di Masyarakat Gg. Swadaya Kelurahan Cempaka Putih Kecamatan Ciputat Timur Tangerang Selatan, dilaksanakan pada Senin, 16 Juli 2018 pukul 08.0012.00WIB Semula akan dilaksanakan di kampung bayam, Ancol namun karena terkendala dengan gedung yang akan digunakan mengalami renovasi yang belum selesai dan membahayakan pesserta pelatihan, tim pelaksana mendiskusikan perpindahan lokasi PKM ke gg Swadaya Kelurahan Cempaka putih ciputat timur.

Pemateri menyampakan bahwa Pengasuhan dan pendidikan di keluarga adalah yang pertama dan utama. Anak dapat tumbuh dan berkembang dengan baik apabila pengasuhan yang dilakukan dalam keluarga sesuai dengan tahap perkembangan dan usianya, juga dengan mengedepankan prinsip-prinsip pengasuhan yang positif. Membangun komunikasi efektif dan menerapkan disiplin positif dalam keluarga merupakan salah satu cara yang dapat Ayah dan Bunda lakukan dengan mendukung optimalisasi perkembangan anak yang meliputi aspek fisik, berfikir, perasaan, dan sosial dalam pengasuhan agar anak tumbuh dan berkembang secara optimal. Komunikasi positif tentu saja dilakukan bukan oleh ibu semata tapi juga ayah, nenek, kakek, dan saudara-saudara dimana anak tumbuh kembang. Namun, yang paling dekat dengan anak tentu ibu, ayah, nenek atau kakek, serta pengasuhnya.

Sehubungan dengan itu, orangorang terdekat perlu mendidik anak dengan pola komunikasi positif. Pendidikan komunikasi positif pada anak penting dilakukan agar anak terlatih untuk mengetahui mana yang baik dan tidak, sehingga tidak asal bicara yang dapat menimbulkan kerusuhan, percekcokan. Seorang anak haruslah diberitahu dan dibina untuk mempertimbangkan apa, siapa, dimana, dan untuk apa dia berbicara. Jika tidak, perilaku kasar cenderung berkembang membentuk karakter anak dan bisa berakibat buruk, lebih ekstrimnya kepribadian yang brutal akan terbangun 
Susianty Selaras Ndari, dkk, KOMUNIKASI POSITIF SEBAGAI UPAYA PERLINDUNGAN ANAK DARI KEKERASAN MELALUI KEGIATAN PARENTING DI MASYARAKAT KEL. CEMPAKA PUTIH KEC. CIPUTAT TIMUR TANGSEL PROVINSI BANTEN . Early Childhood Vol. 3 No. 1, Mei 2019

sendirinya. Pemateri mengtakan

Umumnya kalau sudah terjadi kasus baru kita kalang kabut, tercambuk dan tersadar untuk mencarikan solusinya. Pemateri menyampaikan sejumlah straegi dalam melakukan komunikasi positif dengan anak khususnya pada usia dini. Menurut pakar komunikasi dan linguis sejumlah strategi komunikasi positif ini dianggap efektif dalam membangun karakter dan kepribadian anak

Untuk itu, sebagai orang tua perlu mengupayakan agar kekerasan tersebut sebisa mungkin dicegah dan diatasi dengan cara berikut: melakukan keterbukaan dalam berkomuni kasi dengan anak, khususnya berkaitan dengan kekerasan yang mungkin ada di lingkungan anak. Selain itu mereka memiliki sikap positif terhadap pergaulan anak. Rasa empati pada anak juga ditunjukkan orangtua dalam mencegah tindak kekerasan pada anak (Rini, Fardiah: 2016). Orangtau perlu memupuk komunikasi sejak dini dilakukan bahkan sejak anak dalam kandungan menjadi salah satu pra syarat yang dibutuhkan dalam membangun hubungan orangtua dan anak (Dosen, Iain, \& n.d.). Berdasarakan hasil penelitian tersebut dapat dimaknani bahwa orangtua perlu mengupayakan berkomunikasi secara terbuka dengan anak dan komunikasi dapat dimulai sejak anak dalam kandungan sebagai langkah utama menghindarkan terjadinya kekerasan pada anak.

\section{B. PEMBAHASAN}

Berikut hipotesis yang akan disajikan yang telah diolah dari kuisioner, wawancara terstruktur kemudian ditetapkan sebagai berikut bahwa semakin baik orangtua dalam berkomunikasi dengan anak dalam pengasuhan semakin baik hubungan diantara orangtua dan anak (keduanya). Berdasarkan data dapat disajikan berikut ini:1) Apakah Anda memperhatikan anak dan mendengarkan dengan seksama apa yang ia ucapkan? $70 \%$ orang tua menjawab (ya) $\quad 27 \% \quad$ memilih jawaban (kadang-kadang), $\quad 3 \%$ menjawab (tidak). 2) Apakah Anda mencoba memahami cara anak membangun logika pemikiran anak saat berbicara? Apakah semua orang merasa dipahami saat berbicara dalam keluarga? $80 \%$ orang tua menjawab (ya) untuk dua pertanyaan, $15 \%$ memilih jawaban (kadangkadang) 5\% jawab (tidak). 3) Apakah Anda memberikan waktu anak hingga selesei berbicara sebelum berkomentar?, Apakah ada rasa saling menghormati? 85\% dari orang tua menjawab $(y a)$ untuk dua pertanyaan, $10 \%$ memilih jawab (kadangkadang) dan 5\% menjawab (tidak).

Dari hasil penelitian dapat diartikan bahwa peran orangtua 
Susianty Selaras Ndari, dkk, KOMUNIKASI POSITIF SEBAGAI UPAYA PERLINDUNGAN ANAK DARI KEKERASAN MELALUI KEGIATAN PARENTING DI MASYARAKAT KEL. CEMPAKA PUTIH KEC. CIPUTAT TIMUR TANGSEL PROVINSI BANTEN . Early Childhood Vol. 3 No. 1, Mei 2019

memiliki tanggung jawab untuk membangun relasi positif dalam keluarga yaitu: 1) Keterlibatan: Pengasuhan bersama Bimbingan keluarga Menciptakan hari keluarga Berbagi peran dalam keluarga. 2) Kontribusi: Memiliki role model dalam keluarga, Antisipasi konflik keluarga, Kegiatan bersama keluarga, Menyediakan tempat untuk hari keluarga, Memenuhi kebutuhan anak sesuai kemampuan. 3) Tanggungjawab: Komunikasi yang baik, Mencegah konflik Kepekaan organ tua/suami-istri. Peneliti mengartikan bahwa komunikasi yang baik merupakan salah satu tanggung jawab orangtua dalam pengasuhan anak (Pemberdayaan \& Anak, 2016).

Selain itu para ahli menyatakan bahwa orangtua tua perlu memahami prinsip- prinsip dalm membangun komunikasi dengan anak (Kolucki \& Lemish, n.d.). Prinsip- prinsip tersebut yaitu: 1) komunikasi untuk anak harus sesuai dengan usia dan anak-ramah, dan didukung oleh pedoman untuk: menggunakan bahasa yang sesuai untuk anak, karakter, cerita, music. Menggunakan humor mendorong dan model interaksi positif dan berpikir kritis. 2 komunikasi untuk anak harus alamat anak secara holistik, dan didukung oleh pedoman untuk: menggunakan terintegrasi bukan pendekatan satu-isu untuk komunikasi; menawarkan model positif untuk orang dewasa dalam hubungan mereka dengan anak sebagai manusia penuh dalam hak mereka sendiri; dan menciptakan rasa aman serta nyaman. 3) komunikasi untuk anak harus positif dan berbasis kekuatan dan didukung oleh pedoman untuk: membangun kepercayaan diri serta kompetensi; menggunakan pemodelan positif; termasuk anak sebagai warga aktif belajar tentang dan pemodelan keadilan sosial; dan tidak membahayakan. 4) komunikasi untuk anak harus memenuhi kebutuhan semua, termasuk mereka yang paling kurang beruntung, dan didukung oleh pedoman untuk: mencerminkan martabat masing-masing dan setiap anak dan orang dewasa; inklusif: menghargai semua jenis keragaman; memastikan komunikasi bebas dari stereotip; dan mencerminkan dan memelihara aspek positif dari budaya dan tradisi local.

Diperlukan kerjasama orangtua dan guru dalam berkomunukasi dengan anak agar terjadinya pola komunikasi positif untuk menghindarikan terjadinya kekerasan lisan baik di rumah dan di sekolah. Hal ini diperkuat hasil penelitian yang menyatakan kerjasama yang baik antara orangtua dan guru dalam berkomunikasi dengan anak dapat meningkatkan pembelajaran pada siswa (Age \& Parents, 2006). Hal ini dimaknai bahwa komunikasi positif dilakukan oleh semua pihak agar terjadi 
Susianty Selaras Ndari, dkk, KOMUNIKASI POSITIF SEBAGAI UPAYA PERLINDUNGAN ANAK DARI KEKERASAN MELALUI KEGIATAN PARENTING DI MASYARAKAT KEL. CEMPAKA PUTIH KEC. CIPUTAT TIMUR TANGSEL PROVINSI BANTEN . Early Childhood Vol. 3 No. 1, Mei 2019

hubungan positif dan perilaku positif diantara semua pihak.

\section{KESIMPULAN DAN SARAN}

\section{A. Kesimpula}

Berdasarkan hasil pelaksanan kegiatan dan hasil penelitian (PKM) Komunikasi Positif Sebagai Upaya Perlindungan Anak Dari Kekerasan Melalui Kegiatan Parenting Di Masyarakat Gg. Swadaya Kelurahan Cempaka Putih Kecamatan Ciputat Timur Tangerang Selatan, dan hasil pengolahan data dapat disimpulkan sebagai berikut:

1. Keterampilan membangun komunikasi positif orangtua perlu dibangun dan diasah sebagai fondasi membangun hubungan positif dengan anak.

2. Keterampilan komunikasi positif pada anak penting dilakukan agar anak terlatih untuk mengetahui mana yang baik dan tidak, sehingga tidak asal bicara yang dapat menimbulkan kerusuhan, percekcokan. Seorang anak haruslah diberitahu dan dibina untuk mempertimbangkan apa, siapa, dimana, dan untuk apa dia berbicara.

3. Semakin baik komunikasi yang dilakukan orangtua dengan anakanak dalam pengasuhan semakin baik hubungan diantara keduanya yang akan memberikan keharmonisan hubungan dalam keluarga

\section{A. Saran}

1. Perlu diadakan pelatihan terus menerus kepada orangtua dalam melatih ketrampilan komunikasi positif dengan anak sebagai fondasi membangun hubungan positif di dalam keluarga.

2. Sebaiknya orangtua dan guru bekerjasama dalam berokomunikasi dengan anak agar berdampak positif dengan meningkatnya kemampuan belajar di sekolah.

Pimpinan organisasi perlu melakukan upaya jemput bola dan menjalin kerjasama dengan pihak Universitas dalam upaya peningkatan keterampilan orangtua dalam kegiatan parenting agar pengasuhan anak dalam keluarga terhindar dari segala bentuk kekerasan.

\section{DAFTAR PUSTAKA}

Edi, Riyadi. (2015). Perceraian di Indonesia. Jakarta. Pengadilan Tinggi Agama Jakarta.

Asamenew Demessie Bireda \& Jace Pillay (2018) Perceived parent-child

communication and wellbeing among Ethiopian adolescents, International Journal of Adolescence and Youth, 23:1, 109-117, DOI: 
Susianty Selaras Ndari, dkk, KOMUNIKASI POSITIF SEBAGAI UPAYA PERLINDUNGAN ANAK DARI KEKERASAN MELALUI KEGIATAN PARENTING DI MASYARAKAT KEL. CEMPAKA PUTIH KEC. CIPUTAT TIMUR TANGSEL PROVINSI BANTEN . Early Childhood Vol. 3 No. 1, Mei 2019

10.1080/02673843.2017.12

99016

Grimm et al., (2017) Parent-child communication in sport: Integrating theory into research, Journal of Amateur Sport Special Issue: Family Issues

Susianty Selaras Ndari, Chandrawaty, (2019) Peran Guru Dan Orangtua Dalam Implementasi Sekolah Ramah Anak Tanpa Kekerasan Melalui Parenting Di Paud Bintang Dan Paud Rumahku. DOI: $10.22236 / p s d / 11480$ 49692Project: Prosiding

Kolokium Doktor dan Seminar Hasil Penelitian Hibah

Dea, Julia, Tulung, Peran Komunikasi Keluarga Dalam Mencegah Tindak Kekerasan Anak Di Lingkungan Masyarakat Kelurahan Klabala Kota Sorong. e-journal "Acta Diurna" Volume V. No.3. Tahun 2016 (diakses: 20 januari 2018).

Kristin Zolten, M.A. \& Nicholas Long, Ph.D., $\quad$ 1997, 2006 Department of Pediatrics, University of Arkansas for Medical Sciences Artwork by Scott Snider

Merkley, D., Schmidt, D., Dirksen, C., \& Fulher, C. (2006). Enhancing parent-teacher communication using technology: A reading improvement clinic example. Contemporary Issues in Technology and Teacher Education, 6(1), 11-42.

Liane Wardlow, PhD, Research Scientist, Insights for Innovations. www.ResearchNetwork.Pea rson.com.

Barbara Kolucki, MA Dafna Lemish, $\mathrm{PhD}, \quad$ United Nations Children's Fund (UNICEF) November 2011 ISBN: 9780-578-09512-7

Eka Sapti Cahyaningrum. Prioritas Pendidikan Nilai Pada Anak Usia Dini. (diakses 10 September 2015)

Hidayati Farida, Dian Veronika Sakti Kaloeti, Karyono, 2011. Peran Ayah dalam Pengasuhan Anak, Jurnal Psikologi UNDIP Vol.9 No.1

KPAI. 2017. Data Pengaduan Masyarakat. Jakarta. KPAI

Pranawati, Rita dkk, (2015). Survei Nasional Pengasuhan Anak. Jakarta: KPAI

Pranawati, Rita, (2017). Selamatkan Anak Indonesia. Jakarta: Al Wasath Institut

Rini Rinawati, Dedeh Fardiah, (2016). Efektivitas Komunikasi Antarpribadi dalam Mencegah Tindak Kekerasan terhadap Anak Rini Rinawati dan Dedeh 
Susianty Selaras Ndari, $d k k$, KOMUNIKASI POSITIF SEBAGAI UPAYA PERLINDUNGAN ANAK DARI KEKERASAN MELALUI KEGIATAN PARENTING DI MASYARAKAT KEL. CEMPAKA PUTIH KEC. CIPUTAT TIMUR TANGSEL PROVINSI BANTEN . Early Childhood Vol. 3 No. 1, Mei 2019

Fardiah Jurnal Penelitian

Komunikasi Vol. 19 No.1,

Juli 2016: 29-40 ISSN:

1410-8291 | e-ISSN: 2460-

0172

www.jpk.bppkibandung.id

Susianty Selaras Ndari, dkk.

Pengasuhan Berbasis

Budaya Lokal untuk

Perlindungan Anak, Kemen

PPA 2016.

Ohttp://www.klikpsikolog.com/memban

gun-komunikasi-positif-

orang-tua-anak/ (Diakses:

16 Januari 2018) 